\title{
La construcción \\ de la sentencia en el proceso por audiencias*
}

\section{Fredy Hernando Toscano López ${ }^{* *}$}

Resumen: la tramitación de los procesos mediante audiencia impone al juez la obligación de emitir la sentencia en el curso de ella, por lo que resulta importante buscar una ruta metodológica que le facilite esta tarea. El presente trabajo pretende hacer una propuesta, a partir de los retos prácticos del juez en audiencia, con el objeto de que se satisfagan los requisitos de toda sentencia judicial, en especial el de su motivación.

Palabras clave: motivación, oralidad, audiencias.

\section{The Legal Adjudication in the Hearing Process: A Methodological Proposal}

Aвstract: The handling of cases by audience imposes an obligation to the judge to utter their awards during it. That is why is important to look for a methodological route that helps him in this task. These lines pretend to make a proposal

Fecha de recepción: I6 de junio de 20I6. Fecha de aceptación: 3I de octubre de 2016.

Para citar el artículo: F. H. Toscano López, "La construcción de la sentencia en el proceso por audiencias", Revista de Derecho Privado, Universidad Externado de Colombia, n. ${ }^{\circ}$ I , julio-diciembre de 20I6, 32 I-330. DoI: http://dx.doi.org/Io.I 860I/or 234366.n3 I.Io

$\mathrm{El}$ artículo es inédito, aunque las ideas aquí contenidas fueron expuestas en varios foros durante el año 2015 .

** Magíster en Derecho Privado de la Universidad Carlos III de Madrid, Madrid, España. Profesor del Departamento de Derecho Procesal de la Universidad Externado de Colombia, Bogotá, Colombia. Miembro del Instituto Colombiano de Derecho Procesal y del Instituto Iberoamericano de Derecho Procesal. Contacto: fhtoscano.lopez@gmail.com 
based on the practical challenges of judges in audiences, so that the requirements of the judicial awards will be satisfied, especially their motivation.

KEYwords: Motivation, orality, audiences.

Sumario: Introducción. i. Retos prácticos del juez en audiencia. II. Requisitos de toda sentencia judicial. III. Ruta metodológica para emitir la sentencia durante la audiencia. A. Apartados que el juez debe haber redactado antes de la audiencia. B. Aspectos que el juez debe elaborar durante la fase de instrucción y en los alegatos de conclusión. C. Fase de elaboración final de la sentencia y su exposición "oral". Conclusión. Bibliografía.

\section{Introducción}

La tendencia a tramitar los procesos judiciales mediante audiencias no es novedosa, ni en el ordenamiento jurídico colombiano, en el que rige desde el año I948 el Código Procesal del Trabajo y de la Seguridad Social (en adelante, CPL), ni en el ámbito iberoamericano, donde se contemplan las audiencias desde el año I998, al interior del Código Procesal Civil Modelo para Iberoamérica. Sin embargo, la reciente promulgación en Colombia del Código General del Proceso (CGP) y el Código Procesal Administrativo y de lo Contencioso Administrativo (CPACA) genera algunas preocupaciones entre jueces y litigantes, porque en estas especialidades ha regido tradicionalmente un sistema eminentemente escrito.

Este trabajo hace alusión a los retos que tiene el juez a la hora de emitir la sentencia dentro de la respectiva audiencia, dejando claro cuál debe ser el contenido mínimo de toda sentencia y con el objetivo de proponer una ruta metodológica que le facilite la realización de esta tarea. Desde ya, se advierte que si estos funcionarios utilizan los escollos legales para emitir la sentencia escrita ${ }^{\mathrm{I}}$, o se valen de malas prácticas, como llevar la sentencia escrita a escondidas, ello terminará frustrando todo el tránsito hacia la oralidad.

I Cfr. art. 373 num. 5 CGP. Esta norma le otorga al juez la posibilidad de optar por un receso de hasta dos horas. Y de manera excepcional, de dejar de dictar sentencia oral, indicando solamente el sentido del fallo, para emitir luego una sentencia escrita dentro de los diez días siguientes. De otro lado, el artículo i 82 cPaca establece que el juez, de ser posible, debe informar el sentido de su sentencia en forma oral durante la "audiencia de alegaciones y juzgamiento". Sin embargo, puede consignarlo por escrito dentro de los diez días siguientes. En numeral 3 de esta misma disposición se prevé que "cuando no fuere posible indicar el sentido de la sentencia la proferirá por escrito dentro de los treinta (30) días siguientes, dejando constancia sobre la razón por la cual no pudo anunciar el sentido de la decisión”. Por su parte, el cPL consagra en el artículo 80 (modificado, art. I 2 Ley i I 49 de 2007) que en la audiencia de trámite y juzgamiento del proceso ordinario de primera instancia el juez debe dictar sentencia o decretar un receso de una hora para proferirla. De lo anterior se destaca que el proceso contencioso administrativo facilita al juez que dicte sentencia escrita, y no se le estimula a que al menos intente hacerlo oralmente. 
En todo caso, se resalta que el imperativo de emitir la sentencia durante la audiencia no sólo persigue dar mayor rapidez a la tramitación del proceso, sino que busca que el litigio se resuelva mediante los actos de persuasión de las partes respecto del juez, razón por la cual esta idea solo se logrará cuando haya inmediatez en la respuesta judicial.

\section{Retos prácticos del juez en audiencia}

En buena parte, las dificultades que experimenta el juez en la dinámica de la oralidad son de carácter práctico.

Basta citar tres retos que enfrenta el juez en este nuevo contexto:

I) El tiempo para emitir la sentencia es más limitado, pues pasa de días a sólo horas;

2) El juez ya no tiene la posibilidad de aislarse completamente de las partes para reflexionar sobre la sentencia y construirla en la "soledad de su despacho", sino que, en la mayoría de los casos, las partes -ávidas de solucionar su litigiopresionarán una sentencia inmediata una vez finalicen los alegatos de conclusión; y en tercer lugar,

3) El juez que se dispone a emitir la sentencia ha tenido que presidir previamente una audiencia ${ }^{2}$, generalmente larga y compleja, lo que implica que cuando llega a asumir el fondo del litigio se encuentra en un estado mental y físico de agotamiento.

En síntesis, al juez que pasa de tramitar un proceso escrito a uno oral se le exige emitir una sentencia con todos los requisitos tradicionales, pero en condiciones de mayor presión institucional y en menos tiempo.

\section{Requisitos de toda sentencia judicial}

La sentencia judicial se caracteriza por resolver el fondo de la controversia siguiendo los parámetros de congruencia y de motivación de la decisión. Esto quiere decir que se debe hacer un pronunciamiento expreso sobre las pretensiones, es decir, sobre si quedan probadas en todo o en parte, o bien se niega o accede a las excepciones de mérito que fueron planteadas en el litigio ${ }^{3}$.

En virtud del principio de la congruencia, el juez está obligado a decidir la controversia dentro de los lineamientos que las partes le han trazado, y de esta manera el juez únicamente puede tomar en consideración las pretensiones y las

2 Cfr. art. 373 num. I cGP. Este artículo indica que luego de la audiencia inicial, el juez debe desarrollar la audiencia de instrucción y juzgamiento, para la cual se debe contar con un tiempo razonable que permita llevar a cabo la práctica de pruebas y oír alegatos de las partes; una vez efectuadas estas últimas actuaciones, deberá emitir una decisión oral. Lo mismo ocurre en el proceso contencioso administrativo y en el laboral.

3 Cfr. arts. 278 CGP, I 87 inc. 2 CPACA У 6 I CPL. 
excepciones de mérito expuestas por las partes en los momentos procesales previstos y de acuerdo con los hechos probados 4 . Por vía excepcional, el juez puede declarar probados determinados hechos que se hubieren alegado oportunamente, o que se puedan declarar de oficio 5 .

En este punto es pertinente recordar que los alegatos de conclusión serán expuestos en audiencia, y que las partes pueden incluir en dicho acto procesal una serie de pronunciamientos que hasta el momento no se habían realizado. Por ende, el juez deberá tomar nota atenta de las afirmaciones o negaciones incluidas en el alegato de conclusión, porque de su contenido puede emerger un hecho modificativo o extintivo del derecho sustancial debatido que merezca ser analizado con miras a establecer su acreditación.

Otro requisito de la sentencia es la motivación ${ }^{6}$. Las normas procesales colombianas que se refieren a ella no definen el concepto, y sólo se refieren vagamente a su contenido, indicando que ha de ser "breve" y "precisa", y de otro lado establecen que debe limitarse a hacer un examen de las pruebas -explicando las conclusiones sobre ellas- así como de los razonamientos constitucionales, legales, de equidad y doctrinarios necesarios para fundamentar las conclusiones.

Estas advertencias resultan poco útiles para guiar al juez en la tarea de emitir una sentencia durante la audiencia, por lo que viene bien proponer una guía metodológica para la construcción de la sentencia, especialmente de su motivación.

En resumen, la sentencia requiere resolver el fondo del litigio dentro de los parámetros de la congruencia y de manera motivada.

Así, también la motivación de las sentencias hace posible conocer "los errores del juzgador", por lo que motivación e impugnación vienen a ser conceptos cercanos y, por tanto, toda regulación encaminada a garantizar la motivación redunda en un mejor sistema de impugnación7.

Tradicionalmente, para que se dé cumplimiento a estos requerimientos la sentencia debe contener:

a) Una parte resolutiva en la que se exprese de manera breve y clara a quién se le ha dado la razón, y

b) Una parte motiva en la que se expresen las razones por las que se le dio la razón a una parte en vez de a la otra.

4 "El deber de congruencia civil encuentra su fundamento en el principio dispositivo por ser éste, sin lugar a dudas, la traducción procesal en donde se refleja con mayor fidelidad el respeto a la naturaleza jurídica disponible del derecho material deducido en juicio, por lo que el juez limita su ejercicio jurisdiccional según los intereses de las partes que, libremente[,] circunscriben su litigio a las pretensiones y defensas plateadas": Millán, C., La incongruencia civil, Madrid, Tecnos, I 983 , pp. 22-23. En materia laboral y en el derecho de familia, sin embargo, el principio dispositivo debe entenderse de manera más amplia.

5 Cfr. art. $28 \mathrm{I}$ inc. 3 CGP. Y el inc. 2 del art. I87 CPACA.

6 Cfr. arts. 279 inc. I y 280 inc. I CGP, y art. I 87 inc. I CPACA.

7 Cfr. Calamandrei, P., Proceso y democracia, Héctor Fix Zamudio (trad.), Buenos Aires, ejea, i960, I I 8. 


\section{Ruta metodológica para emitir la sentencia durante la audiencia}

A fin de que el juez pueda resolver el fondo del litigio, cumpliendo los requisitos de congruencia y motivación dentro del esquema del proceso por audiencias, es necesario que adopte una ruta metodológica que le sirva como guía para la acción, antes, durante y en la finalización de la audiencia.

En estas líneas se propondrá un método de construcción de la sentencia como sucesión de tres tareas:

I) Aspectos de la sentencia que podrían construirse antes de la audiencia;

2) Temas que deben elaborarse durante la fase de instrucción y alegatos de conclusión, y

3) Elaboración final de la providencia.

En todo caso, la premisa general es que si el juez pretende dictar la sentencia dentro de la audiencia debe haber realizado siempre un concienzudo examen previo del caso concreto, a partir de los fundamentos de hecho expuestos en la demanda o contestación, y de las pretensiones y excepciones de mérito que se le hubieren planteado.

La falencia de este estudio previo hará imposible alcanzar el propósito de congruencia y motivación. Adicionalmente, los asistentes a la audiencia siempre sabrán qué tanto se preparó el juez para dictar la providencia.

\section{A. Apartados que el juez debe haber redactado antes de la audiencia}

Como resultado del estudio previo del expediente escrito, el juez puede tener ya redactados antes de la audiencia por lo menos cuatro aspectos que son imprescindibles en toda sentencia:

I) Un breve apartado que se refiera al tipo de proceso, haciendo una síntesis de su naturaleza, e indicando el tema de prueba (p. ej., divorcio, restitución de inmueble arrendado, reivindicatorio, reparación directa derivada del daño antijurídico causado por una acción u omisión, petición de pensión de vejez) que le sirva de encabezado a su sentencia.

2) Un acápite sobre la "regularidad del proceso" en la que se deje plasmada la idea de que el proceso ha sido llevado en debida forma y que luego de tramitadas las etapas del proceso no se observan causales de nulidad que puedan afectar el debido proceso, por lo que es posible dictar una sentencia de fondo.

3) En tercer lugar, se recomienda un apartado que trate del "problema jurídico", en el que se planteen, al menos de manera provisional, el problema de hecho y el problema de derecho que se van a resolver en el proceso ${ }^{8}$, los cuales

8 "Entre el problema de hecho y el de derecho existe un eslabón lógico que puede denominarse de 'tipificación de los hechos' encaminado a establecer: a qué hipótesis normativa corresponden 
no cambian en función de lo que acontezca en la audiencia, salvo casos muy excepcionales.

La construcción del "problema de hecho" se realiza a partir de las alegaciones de las partes formuladas en la demanda y en la contestación, pero también, como ya ha sido realizada la audiencia inicial, se puede extraer de la fase de la "fijación del objeto del litigio"?.

Recuérdese de manera breve que el problema de hecho consiste en precisar qué hechos deben ser probados para que la pretensión salga avante, y/o qué hechos deben quedar probados para que la excepción de mérito sea apreciada. Por ende, si el proceso trata de la responsabilidad civil extracontractual, es clara la carga de prueba que soporta el demandante: el daño, la acción u omisión del demandado causante del daño, y la culpa de este último. Pero también es posible anticipar que la prosperidad de la acción se puede ver destruida si el demandado logra probar, por ejemplo, la culpa exclusiva de la víctima.

Por su parte, el problema de derecho tiene que ver con qué norma se podría aplicar al caso concreto, para obtener de ella la aplicación de la consecuencia jurídica en la sentencia. Así por ejemplo, en un caso de responsabilidad civil, el juez puede tener ya preparada una referencia escrita sobre el concepto y el alcance general de la "responsabilidad civil contractual" y la "responsabilidad civil extracontractual", de donde le será posible extraer las normas jurídicas que le servirán para plantear el problema de derecho.

4) En cuarto lugar, y con miras a ir anticipando la resolución del problema de hecho, el juez debería redactar un apartado sobre la "prueba de interrogatorio de parte", cuyo contenido serán las preguntas y respuestas formuladas por ambas partes de manera oficiosa o a solicitud de parte, sobre todo aquellas que hubieren sido calificadas como susceptibles de confesión, y en caso de no comparecencia injustificada, también se recomienda tener redactado un apartado con similar contenido.

En todo caso, en este apartado no se deben anticipar las conclusiones del juez, por cuanto la confesión es susceptible de "infirmación" Iо y debe valorarse

los hechos - y sólo después de agotada esta fase será posible establecer las consecuencias que 'ex lege' se siguen de allí y precisar, entonces, qué derechos o qué obligaciones corresponden en concreto a cada parte": Bigliazzi-Geri, L., en aA.vv., Derecho civil: hechos y actos jurídicos, t. I, vol. 2, Fernando Hinestrosa (trad.), Bogotá, Universidad Externado de Colombia, reimpr., I995, II 39 .

9 Esta etapa procesal es la oportunidad para que -por economía procesal- las partes puedan dar por probados los hechos susceptibles de confesión en que estuviesen de acuerdo. Cfr. art. 372 num. 7 inc. 4 CGP y art. 373 num. 2 inc. 2.

Io Cfr. art. I97 CGP, en virtud del cual se establece la infirmación de la confesión, dado que dicha figura admite prueba en contrario. 
en conjunto con los demás medios de $\operatorname{prueba}^{\mathrm{II}}$; de manera que hacer algún pronunciamiento al respecto constituiría una especie de prejuzgamiento.

Un aspecto de la mayor importancia y que hace parte de esta estrategia metodológica es recomendar que la redacción de cada uno de estos componentes se realice de manera autónoma y completa, de modo que el juez pueda utilizar cada componente como pieza de un "rompecabezas", que pueda acomodar de cara a su exposición en la audiencia.

\section{B. Aspectos que el juez debe elaborar durante la fase de instrucción y en los alegatos de conclusión}

Durante la fase de instrucción del proceso y alegatos de conclusión se propone que el juez tenga una actitud vigilante sobre los actos procesales que allí se producen, porque este es el escenario para encontrar los argumentos "de hecho" y "de derecho" para resolver precisamente el problema de hecho y de derecho que ya se ha planteado. Así pues, el juez debe adoptar una perspectiva crítica, preguntándose continuamente si los medios de prueba que se están practicando en su presencia (especialmente, los testimonios, la contradicción del perito ${ }^{\mathrm{I} 2} \mathrm{y}$ la exhibición de documentos) contribuyen a despejar el problema de hecho y de derecho elaborado previamente.

Por ende, es recomendable que el juez tome nota de las preguntas y respuestas más importantes de los testigos o los peritos, esto es, de las que le hubieren causado mayor impacto, por haberle convencido de la verosimilitud de las alegaciones de las partes, las que en últimas le habrán servido para formar su convencimiento. En este orden de ideas, sería recomendable que el juez pudiera identificar, por ejemplo, el número de pregunta, la frase textual con la que ha respondido la parte o el testigo, y que le resultó útil para darse por convencido de una alegación, de la misma manera que se recomienda que se concentre en las alegaciones que debe desechar por encontrarlas no probadas.

El otro momento clave de la construcción de la sentencia es el que destina el juez a escuchar los alegatos de conclusión. Idealmente, si los alegatos de conclusión han sido elaborados de manera cuidadosa, suministrarán al juez la argumentación suficiente para resolver el problema de hecho y de derecho, sólo

I I Cfr. art. I 76 CGP. Aquí se consagra el deber del juez de valorar los medios de prueba en conjunto, aplicando las reglas de la sana crítica, en todo caso, teniendo en cuenta las solemnidades establecidas en la ley sustancial dirigida a la validez y existencia de algunos actos particulares.

I 2 Cfr. arts. 228 y 23 I CGP. La actual regulación de la contradicción del dictamen pericial hace necesaria la asistencia del perito a la audiencia, salvo en casos taxativos, tales como procesos de filiación, interdicción por discapacidad mental absoluta e inhabilitación por incapacidad relativa, en los cuales la norma avala presentarlos por escrito. Sin embargo, en el proceso contencioso administrativo, el régimen de contradicción del dictamen pericial es más amplio: cfr. arts. 2 I 8 , 2 I 9 Y 220 CPACA. 
que con la ventaja de que cada parte mostrará su propia hipótesis, de tal forma que al juez le bastará con escoger entre una y otra, de acuerdo con el estándar de prueba de la "probabilidad preponderante" ${ }^{3}$.

En resumen, la actitud del juez durante los actos de prueba y de la exposición de los alegatos ha de ser "receptiva" de toda la información verbal y no verbal de los testigos y los peritos, así como de las demás actitudes de las partes, pues la aspiración de la oralidad es que la resolución del problema de hecho y de derecho se logre con fundamento en lo ocurrido en la audiencia.

\section{Fase de elaboración final de la sentencia y su exposición "oral”}

El receso que puede decretar el juez en la audiencia ${ }^{\mathrm{I} 4}$ podría ser insuficiente para la elaboración final de la sentencia, lo que simplemente pone de presente que el legislador -en uso de su libertad de configuración- estimó que ese era el tiempo promedio para elaborar un fallo.

Sin embargo, suponiendo que se han seguido los pasos anteriores, el juez podría utilizarlos para:

a) Organizar los apartados que ya hubo de redactar en las fases anteriores, y

b) Redactar la parte resolutiva del fallo, así como la parte motiva, lo que es sin duda un desafío grande, mas no imposible.

De esta manera, la sentencia dentro de la audiencia podría tener la siguiente estructura:

a) Para empezar, la identificación de los datos del expediente, las partes y la naturaleza del proceso judicial;

b) Debería proseguir con las piezas ya redactadas relativas a la regularidad formal del proceso, una síntesis del tema de prueba y un apartado sobre la legitimación en la causa, la que hasta el momento de la audiencia podría no estar clara;

c) Seguidamente, el juez debería hacer alusión al problema jurídico (de hecho y de derecho), el que difícilmente habrá variado durante la audiencia, para luego proceder a la valoración probatoria.

En este punto conviene advertir que el concepto mismo de valoración es controversial, y tampoco existe unanimidad frente al orden que debe seguir el juez en el momento de producción de la sentencia. Esto es, que en realidad no se sabe si: a) primero el juez concluye cuál de las hipótesis está llamada a prosperar y luego redacta la justificación de su elección (es decir la motivación), o si, por el contrario, b) el juez pondera, valora y ensaya argumentos para luego extraer la conclusión sobre a quién debe dar la razón.

I 3 Cfr. Gascón Abellán, M., Cuestiones probatorias, Bogotá, Universidad Externado de Colombia, 2012,78 .

I4 Cfr. arts. 373 num. 5 CGP y 80 CPL. 
Lo cierto es que la costumbre judicial nos indica que, al menos formalmente, lo que primero aparece en la sentencia, sea escrita o bien leída en audiencia, es la motivación, y luego la parte resolutiva.

Pues bien, siguiendo ese orden, lo que se aconseja es que luego de presentado el problema jurídico, el juez haga referencia a las hipótesis del demandante y el demandado en términos neutros, afirmando cuál es la posición del demandante y cuál de la del demandado, y paso seguido, examine esas hipótesis a la luz de los medios de prueba practicados dentro y fuera de las audiencias.

Nótese que es pertinente este orden, porque si la sentencia judicial se considera la respuesta institucional a un litigio, tiene sentido que el juez identifique primero el problema jurídico, y a renglón seguido exprese las dos hipótesis enfrentadas que le darían respuesta, para luego mostrar, con fundamento en los medios de prueba, cuál de ellas es la más probable.

De esta manera, resulta fundamental que el juez incluya en esta etapa, que generalmente identificamos como "considerativa", el análisis del interrogatorio de parte-que, se recordará, ya está esbozado previamente en su parte objetiva-, para luego hacer lo propio con los demás medios de prueba, concluyendo con una síntesis de lo que está probado y lo que no. Posterior a ello, el juez debe resolver el problema de derecho encuadrando las alegaciones probadas en el supuesto de hecho de la norma que ha encontrado aplicable al caso.

El apartado final es la parte resolutiva del fallo, la que, muy seguramente, ya está clara en la mente del juez desde el comienzo de la elaboración de la sentencia. Esta, por supuesto, como ya se ha indicado, debe hacer precisión respecto de todas y cada una de las pretensiones y de las excepciones de mérito, de manera que quede claro si prosperan de manera total o parcial, por supuesto, respetando los límites de la congruencia.

\section{Conclusión}

Para concluir, debe advertirse que el modelo anteriormente propuesto para la emisión de la sentencia dentro de la audiencia solo es posible si el juez tiene clara su misión institucional de resolver el litigio, dejando de lado esa idea -a veces promovida desde las altas cortes- según la cual la sentencia tiene fines pedagógicos, y en consecuencia, habría que explicar cada concepto jurídico, su origen histórico y su desarrollo jurisprudencial previo; porque en realidad el destinatario de la justicia no va al proceso a que lo aleccionen, ni el juez está para demostrar su vasta cultura en la sentencia, sino únicamente para decidir la controversia que se le ha planteado.

En consecuencia, la sentencia proferida en audiencia debe hablar más del problema real del ciudadano de carne y hueso que pide justicia, y suprimir aquellas citas doctrinales o jurisprudenciales que no sean estrictamente necesarias para explicarle por qué ganó o perdió en el proceso. 


\section{Bibliografía}

Bigliazzi-Geri, L., Derecho civil: hechos y actos jurídicos, t. I, vol. 2, Fernando Hinestrosa (trad.), Bogotá, Universidad Externado de Colombia, reimpr., I 995.

Calamandrei, P., Proceso y democracia, Héctor Fix Zamudio (trad.), Buenos Aires, EJEA, I96o.

Ferrajoli, L., "El papel de la función judicial", en aA.vv., furisdicción de argumentación en el Estado constitucional de derecho, México, Unam, 2005.

Gascón Abellán, M., Cuestiones probatorias, Bogotá, Universidad Externado de Colombia, 2012.

Millán, C., La incongruencia civil, Madrid, Tecnos, 1983. 